\title{
Study on Urbanization Level of Shanxi Province
}

\author{
Shi Rui \\ Shaanxi Normal University \\ Xian, China \\ 283443137@qq.com
}

\begin{abstract}
As a fundamental way to coordinate the integration of urban and rural areas, Urbanization symbolizes a country's modernization and social and economic development level. The urbanization of Shanxi Province is below the average level of China and has low quality. Therefore the method of measuring the urbanization level of Shanxi Province is important as well as fully understanding the current situation and existing problems of the urbanization in Shanxi Province. The article evaluates the current situation of urbanization in Shanxi Province from the perspective of urbanization rate, economic development condition, people's living conditions and infrastructure conditions by using principal component analysis. The results show that the quality of urbanization in Shanxi Province is low and the structure of urbanization is inappropriate. In the end, some suggestions are put forward for these specific problems.
\end{abstract}

Keywords-Shanxi Province; Urbanization; Principal component analysis

\section{INTRODUCTION}

Urbanization symbolizes a country's modernization and social and economic development level. It's an important driving force for the adjustment of industrial structure and a fundamental way to coordinate the integration of urban and rural areas [1]. Urbanization plays an irreplaceable role in promoting economic growth and improving people's living standards. Shanxi Province is a province in the central part of China. Its urbanization level reflects the economic, social, cultural and environmental development of Shanxi Province. Therefore, the urbanization level of Shanxi Province is measured by scientific method. System research and discussion on Shanxi Province urbanization level for the transformation of economic development and construction has very important practical significance, helps to suit the remedy to the case, find out the countermeasures to solve the problem, to Shanxi Province urbanization level and the improvement of quality. This will have a qualitative leap to the economic growth of Shanxi Province. Therefore, it is necessary to study the urbanization level of Shanxi Province.

This paper makes an overall assessment of the quality of urbanization in Shanxi Province from the aspects of urbanization rate, economic development, people's living conditions and infrastructure conditions.After 11 cities as the research object, the search for the population, economy, people's life of index data, using principal component analysis on the 17 cities in Shanxi Province urbanization level to score. The status quo and existing problems of urbanization in Shanxi Province are analyzed. According to the problems in the process of urbanization in Shanxi Province, the corresponding Suggestions and countermeasures are put forward, hoping to provide some help to the urbanization development of Shanxi Province.

\section{StUdy ON URBANIZATION LEVEL OF SHANXI PROVINCE}

\section{A. Analysis on the comprehensive development level of urbanization in Shanxi Province}

In recent years, the economic development level of Shanxi Province has been rising steadily, and the urbanization level has also been developing rapidly. By the end of 2015, China's urbanization rate had reached $56.10 \%$, and that of Shanxi Province was $55.02 \%$. The urbanization development level of Shanxi Province was still 1.08 percentage points lower than the national average. In 2015 rankings of urbanization in the 31 provinces and cities nationwide, Shanxi Province ranks 16th, urbanization rate in the lowest level, our province and the rest of the developed province urbanization level has obvious gap, specific ranking as shown in figure 1 .

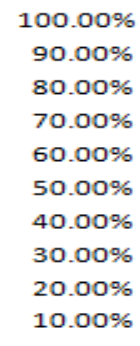

$10.00 \%$

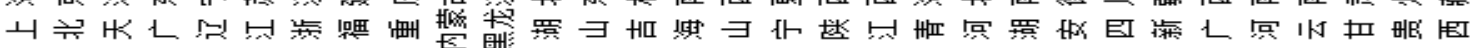

Fig. 1 Urbanization rate of 31 provinces and cities in 2015 


\section{B. Economic development status}

From 2000 to 2000, Shanxi economy overall development level is relatively stable, GDP and per capita GDP rise year by year, in 2015 in Shanxi Province GDP amounted to 1.28026 trillion yuan, per capita GDP amounted to 35018 yuan. The regional GDP of Shanxi Province has been lagging behind the national average for many years, and the gap has been widening over time. The economic development level of Shanxi Province is still relatively backward.

\section{People's living standards}

In 2015, the average disposable income of urban residents in Shanxi province was 25,827.72 yuan, and that of rural residents reached 9,453.91 yuan. In 2015, the average income of urban residents nationwide was 31,194.83 yuan, while that of rural residents was 11,421.71 Yuan. It can be seen that people's living standards in Shanxi Province are lower than the national average. In addition, engel's coefficient can be used to comprehensively evaluate the living standard of a local people. According to the survey, the engel coefficient of urban and rural households in 2015 was $25.2 \%$ and $29 \%$ respectively. Below the national average.

\section{Current situation of infrastructure construction}

The construction degree of a local infrastructure is an important index to evaluate the urbanization development of the region and a solid foundation for the stable and sustained economic development of a region [2]. In 2015, up to 20.26 billion yuan was invested in infrastructure projects in Shanxi Province. Investment in various kinds of infrastructure projects in our province increased by $10 \%$ compared with the growth rate in 2014, which occupies an important position in social investment. It can be seen from table 1 that the urban water use penetration rate and urban gas penetration rate of Shanxi Province are higher than the national average respectively. The data of the number of public transport vehicles, the area of roads and the area of parks and green areas per capita in Shanxi Province are still lower than that of the whole country.

TABLE I MUNICIPAL FACILITIES LEVEL OF URBANIZATION IN CHINA AND SHANXI PROVINCE IN 2015

\begin{tabular}{|c|c|c|c|c|c|}
\hline Index & $\begin{array}{l}\text { Urban water } \\
\text { penetration rate } \\
(\%)\end{array}$ & $\begin{array}{l}\text { Urban } \\
\text { penetration } \\
(\%)\end{array}$ & $\begin{array}{l}\text { Public transport } \\
\text { vehicles per } 10,000 \\
\text { people (beacon) }\end{array}$ & 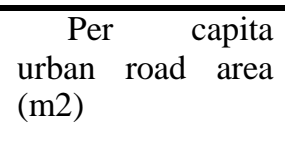 & $\begin{array}{l}\text { Per capita park } \\
\text { green area (m2 / } \\
\text { person) }\end{array}$ \\
\hline ide ${ }^{\text {Nationw }}$ & 98.07 & 95.30 & 12.99 & 15.34 & 14.12 \\
\hline Shanxi & 97.26 & 95.18 & 10.01 & 15.26 & 13.35 \\
\hline $\begin{array}{c}\text { Shanxi/ } \\
\text { Nationwide }\end{array}$ & 0.99 & 0.99 & 0.77 & 0.99 & 0.94 \\
\hline
\end{tabular}

The data come from the urban and rural construction statistical yearbook

III. EVALUATION ON THE COMPREHENSIVE DEVELOPMENT LEVEL OF PREFECTURE-LEVEL URBANIZATION IN SHANXI PROVINCE

A. Comprehensive evaluation system index system construction and index selection

This paper respectively from the population, economy, people's life and the environment in 11 cities in Shanxi Province the aspects of urbanization comprehensive development level

Evaluation [3], constructs the elements from the system layer, layer and index layer three aspects, such as index system framework, specific see table 2 . 
TABLE II EVALUATION INDEX SYSTEM OF URBANIZATION

\begin{tabular}{|c|c|c|}
\hline System layer & Element Layer & Index layer \\
\hline \multirow[t]{24}{*}{ urbanization level } & \multirow{2}{*}{$\begin{array}{l}\text { Urbanization } \quad \text { of } \\
\text { population }\end{array}$} & Urbanization rate $\mathrm{X} 1$ \\
\hline & & Urban employees/Total employees X2 \\
\hline & \multirow{7}{*}{$\begin{array}{l}\text { Economic } \\
\text { urbanization }\end{array}$} & Population density X3 \\
\hline & & The proportion of non-agricultural workers \\
\hline & & $\mathrm{X} 4$ \\
\hline & & Average GDP X5 \\
\hline & & Indusrial output/GDP X6 \\
\hline & & $\begin{array}{l}\text { Output value of secondary industry and } \\
\text { tertiary industry /GDP X7 }\end{array}$ \\
\hline & & $\begin{array}{l}\text { The secondary industry accounts for the } \\
\text { proportion of fixed asset investment } \mathrm{X} 8\end{array}$ \\
\hline & \multirow[t]{5}{*}{ Lifestyle urbanization } & $\begin{array}{l}\text { The tertiary industry accounts for the } \\
\text { proportion of fixed asset investment } X 9\end{array}$ \\
\hline & & Urban disposable income X10 \\
\hline & & $\begin{array}{l}\text { The per capita consumption expenditure of } \\
\text { urban resident X11 }\end{array}$ \\
\hline & & $\begin{array}{l}\text { The number of high school students per } \\
\text { thousand X12 }\end{array}$ \\
\hline & & The number of cars per person $\mathrm{X} 13$ \\
\hline & \multirow{3}{*}{$\begin{array}{l}\text { Infrastructure } \\
\text { urbanization }\end{array}$} & Total Social Retail Sales X14 \\
\hline & & $\begin{array}{l}\text { The number of beds per thousand people } \\
\text { X15 }\end{array}$ \\
\hline & & Internet broadband access users X16 \\
\hline & \multirow{7}{*}{$\begin{array}{l}\text { Environmental } \\
\text { urbanization }\end{array}$} & Highway mileage X17 \\
\hline & & $\begin{array}{l}\text { The number of buses operated by buses } \\
\text { X18 }\end{array}$ \\
\hline & & Urban road area at the end of the year X19 \\
\hline & & Total urban water supply X20 \\
\hline & & Green coverage area of built-up area X21 \\
\hline & & Sewage disposal rate $\mathrm{X} 22$ \\
\hline & & $\begin{array}{l}\text { The number of days the air quality meets } \\
\text { the standard X23 }\end{array}$ \\
\hline
\end{tabular}

B. Measurement method of comprehensive development level of urbanization in Shanxi Province

Software for the SPSS22.0 11 provincial level city comprehensive analysis to evaluate the degree of urbanization development, principal component analysis is adopted in the analysis of the review process for each variable object for data analysis [4].
1) Dimensionless original data

First of all, the raw data of 11 cities are dimensionless, which reduces the data difference and makes the data distribution stable to a certain extent. The method of data dimensionless processing is as follows.

$$
\mathrm{Y}_{\mathrm{ij}}=\left(\mathrm{V}_{\mathrm{ij}}-\mu_{\mathrm{i}}\right) /\left(\mathrm{V}_{\mathrm{imax}}-\mathrm{V}_{\mathrm{imin}}\right)
$$

In the formula, $V_{i j}$ is the original data of the $\mathrm{j}$ sample city of item $i$ evaluation index. $\mu_{i}$ is the average value of the $i$ evaluation index. $V_{\text {imax }}$ is the maximum value of the original data of item $i$ evaluation index of the sample city. $V_{\text {imin }}$ is the minimum value of original data of item i evaluation index of 
sample city. $\mathrm{Y}_{\mathrm{ij}}$ is the index utility value of the $\mathrm{j}$ sample city of item $i$ evaluation index.

2) Variance analysis and score calculations

Using SPSS22.0 the standardized data processing software, and then principal component analysis was carried out on the standardization of data can get the characteristic value and the variance contribution rates of the principal component, load matrix of principal component and principal component score coefficient matrix.

TABLE III CHARACTERISTIC VALUE AND VARIANCE CONTRIBUTION RATE

Component Initial eigenvalue

Component

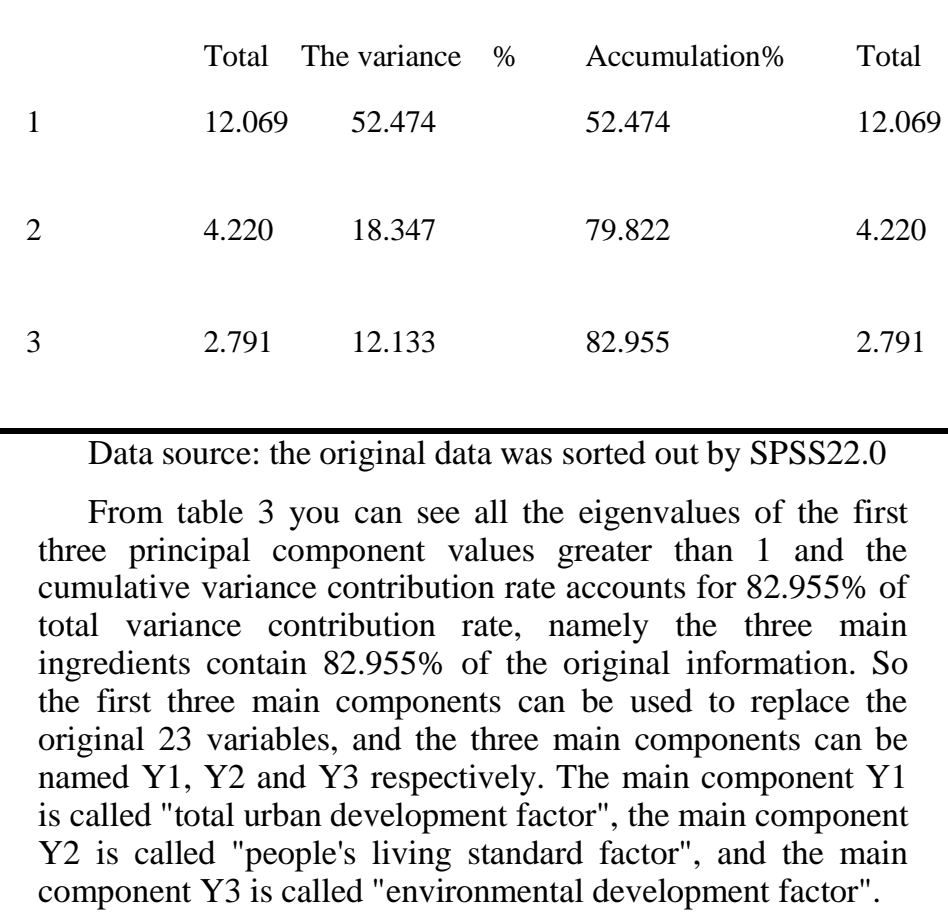

The

otal variance $\%$ Accumulation $\%$ Total The variance $\%$ Accumulation $\%$ 
It can be seen from table 4 that the urbanization level of Shanxi Province 11 is generally not high, only three cities have a positive comprehensive score, among which Taiyuan city ranks among the top in the score of three main components. The remaining eight prefecture-level cities had negative urbanization levels, while the lowest three cities were Shuozhou, Xinzhou and Lvliang.

\section{CONCLUSION}

\section{A. Problems in the urbanization of Shanxi Province}

1) Industrialization and urbanization are not in harmony

Industrialization has a very important role to the development of urbanization, industrialization to promote the development of urbanization, urbanization provide advanced means of production, the coordinated development of the level of urbanization and industrialization should be good. The urbanization rate of Shanxi Province is increasing year by year, but the industrialization rate has been decreasing year by year since 2011, and the gap between the two is getting bigger. The difference was $-7.9 \%$ in 2005 , and by 2015 it had risen to $20.87 \%$, contrary to Chenery's "development model". It can be seen that there is a problem of uncoordinated industrialization and urbanization development in Shanxi Province [5].

2) Obvious internal differences in the level of urbanization development

Taiyuan had the highest urbanization rate among prefecture-level cities in Shanxi Province in 2015, and its urbanization rate was $79.46 \%$, far exceeding the national average urbanization rate and the average urbanization rate in Shanxi Province. The lowest urbanization rate in Shanxi Province is luliang, with an urbanization rate of $46.24 \%$, which is far behind that of Taiyuan. In the evaluation of the comprehensive development level of urbanization in prefecture-level cities of Shanxi Province, the difference between the highest score and the lowest score of the comprehensive development level of urbanization is 2.55, which is quite large. Therefore, it can be concluded that the urbanization development level of Shanxi Province is significantly different.

\section{3) The low quality of the city}

In terms of total urban development factor, people's living standard factor and environment development factor, at least 5-6 cities in Shanxi Province score negative in each factor. In the final comprehensive score of urbanization level, only 3 cities scored positively, while the remaining 8 cities scored negatively. It can be seen that the urbanization quality of Shanxi Province is not high.

\section{B. Thinking on the urbanization development strategy of Shanxi Province}

1) Optimizing the industrial structure of Shanxi Province and coordinating the development of industrialization and urbanization

The urbanization level of Shanxi Province is not in harmony with the industrialization level, and its tertiary industry structure is not reasonable, which seriously restricts the improvement of the economic development and urbanization level of Shanxi Province. Therefore, it is very important to adjust the industrial structure and coordinate the development of industrialization and urbanization. First of all, we can develop modern agriculture, learn from the American agricultural industrialization management mode, and play the role of the market in agricultural industrialization management [6]. The government should also provide support and assistance to the development of agricultural industrialization, mainly through organization and credit support. Second, we will promote the structural upgrading of the secondary industry and take the road of new intensive industries [7]. Third, we will increase support for the service sector in the tertiary industry and promote Shanxi as a tourist destination.

2) Increasing support for areas with low levels of urbanization and narrow regional differences in urbanization

The comprehensive development level of urbanization in prefecture-level cities in Shanxi Province is obviously different, and the cities with low urbanization rate are far lower than the average urbanization rate of Shanxi Province and the whole country. Cities with low comprehensive development level of urbanization include Yuncheng, Xinzhou, Linfen and Lvliang. The government should enhance the support to this a few cities, adjust measures to local conditions for development of local economy industry, focus on labor and resources to speed up the construction of the industrial garden, reasonably adjust the local industrial structure, giving full play to the advantages of the place[8].

\section{3) Improving the quality of urbanization}

In Shanxi Province urbanization should not only pursue the increase of urbanization rate of urbanization is not only on behalf of the urbanization of population, also on behalf of the economy, society, environment and people's life of urbanization. Therefore, in the process of accelerating urbanization, we will increase the security fund for people's livelihood, and take into account people's food, clothing, housing, transportation and other aspects to improve people's quality of life. To strengthen the construction of urban infrastructure, such as establishing the etheric part of good traffic network system, make people travel more convenient, promote the population, resource and the exchange of information, strengthen the radiation of the city [9]. Improving the ecological environment of the city. Reinforcing people's ideas about protecting the environment. We will improve the treatment technology of urban sewage and domestic waste, and increase the rate of sewage disposal and the rate of harmless disposal of garbage. 


\section{REFERENCES}

[1] Boyee, R.R. The wave theory analog Approach[R]. The edge of the Metropolis,British Columbia Geohical Series, 1999, 7(3): 1-40.

[2] Gott man J. The Urbanization of the Northeastern Seabord of the Unite States[J]Megalopolis. Cambridge, The M. L.T Press, 2001, 85.

[3] J. Davis, J.V Henderson. Evidence on the Political economy of the urbanization Process[J]. Journal of Urban Economies, 2003, (53): 98-I25.

[4] Jin Bin Measurement of comprehensive urbanization level in Shanxi Province [J]. Hebei enterprise,2016,02:48-50.

[5] Liu Xiaolan, Zhang Xingmei. Problems and countermeasures in the process of urbanization in Shanxi Province [J]. Journal of xinzhou normal university,2013,05:44-46.

[6] li Jiangsu,Wang Xiaorui,Miao Changhong,Liu Jiajun. Analysis on the coordination degree between urbanization level and urbanization quality_-Based on Henan province [J]. Economic geography ,2014,10:70-77.

[7] Niu Xiaochun, Du Zhongchao, Li Tongsheng. Evaluation of regional urbanization level from the perspective of new urbanization-Take 10 provincial cities in shaanxi province for example [J]. Arid geography, 2013,02:354-363.

[8] Wang Yang,Fang Changling,Wang Zhenbo. Comprehensive evaluation of the urbanization level of county areas in China and the division of different types of areas [J]. Geographical research,2012,07:1305-1316.

[9] Youxin Study on urbanization level and economic population development in western China-Based on the panel data of 12 provinces and regions in western China from 2000 to 2010 [J]. Geological Sciences,2015,03:268-274. 